\title{
Synthesis and Characterization of Superhydrophobic-Superoleophobic and Anti-Corrosion Coatings via Sol-Gel Process
}

\author{
Mohammad Reza Heshmati ${ }^{1}$, Sahar Amiri ${ }^{1}$, Maryam Hosseini-Zori ${ }^{2}$ \\ ${ }^{1}$ Department of Polymer Engineering, Science and Research Branch, Islamic Azad University, Tehran, Iran \\ ${ }^{2}$ Department of Inorganic Pigments and Glazes, Institute for Color Science and Technology (ICST), Tehran, Iran \\ Email: ^Polymer.amiri@gmail.com
}

How to cite this paper: Heshmati, M.R., Amiri, S. and Hosseini-Zori, M. (2020) Synthesis and Characterization of Superhydrophobic-Superoleophobic and Anti-Corrosion Coatings via Sol-Gel Process. Open Journal of Organic Polymer Materials, 10, 1-15.

https://doi.org/10.4236/ojopm.101001

Received: December 16, 2019

Accepted: January 5, 2020

Published: January 8, 2020

Copyright $\odot 2020$ by author(s) and Scientific Research Publishing Inc. This work is licensed under the Creative Commons Attribution International License (CC BY 4.0).

http://creativecommons.org/licenses/by/4.0/

\begin{abstract}
Superoleophobic nanocomposite coatings with improved hydrophobic properties were obtained by incorporation of a perfluoroalkyl polymer in hybrid sol-gel matrix containing silica and titania nanoparticles. $\mathrm{SiO}_{2}$ and $\mathrm{TiO}_{2}$ nanoparticles were synthesized based on sol-gel precursors utilizing tetraethyl orthosilicate, 3-glycidoxypropyl trimethoxysilane, and tetra (n-butyl orthotitanate). SEM and EDX images of the coating demonstrated that a Silica nanosphere had been aggregated in superporous structure. The analysis results show that nano-sized inorganic particles $(10-20 \mathrm{~nm})$ have a uniform distribution and dispersion. By increasing the PFOTES, the oleophobicity of coatings increased due to lowering of surface energy in the presence of fluoropolymer. Results of EIS measurement show that PFOTES and $\mathrm{TiO}_{2}$ nanoparticles increased anti-corrosion property of hybrid coatings. This method introduces a simple way to produce water- and oil-repellent self-cleaning coatings on large areas of different substrates like glass, ceramic, metal and composites.
\end{abstract}

\section{Keywords}

Super-Hydrophobic, Super-Oleophobic, Sol-Gel, Perfluoroalkyl Polymer $\left({ }^{1} \mathrm{H},{ }^{1} \mathrm{H},{ }^{2} \mathrm{H},{ }^{2} \mathrm{H}\right)$-Perfluorooctyltriethoxysilane, Contact Angle

\section{Introduction}

Applying protective films or coatings on the surface of various materials protect them from corrosion, scratch or abrasion resistance and also enhance the desired properties of the substrate such as adhesion, optical appearance, bioactivity, hydrophilic or hydrophobic, antimicrobial and anti-reflective [1] [2]. One of 
the best methods for coating materials at low temperature and pressure is a sol-gel process which is based on inorganic and organic components as a homogeneous hybrid that causes the formation of a covalent bond between them [3] [4].

In last decades, superhydrophobic and super-oleophilic coatings are interested in the field of filtration, especially for oil/water separating industry. Various researches were done in this area which focused on the fabrication of surface roughness or modification with hydrophobing agents [5] [6]. Using fluorinated based materials is an appreciated method which reduces the surface energy of materials. Composite particles of silica/fluoropolymer were prepared using an emulsion mediated sol-gel process, and then these composite particles were applied to various substrates to mimic the surface microstructures of lotus leaves [7] [8] [9] [10]. The main advantage of the hybrid coating, in comparison with an inorganic coating, produced from pure monomer is its more plastic behavior due to the presence of organic chains. The organic coating that has been used for corrosion resistance can be improved by adding nanoparticles to its formula. Decreasing particle size and followed that increasing SSA of particles, especially in nanoscale can improve the surface protection, such as $\mathrm{SiO}_{2}, \mathrm{Al}_{2} \mathrm{O}_{3}, \mathrm{ZnO}$ and $\mathrm{TiO}_{2}$ [11] [12] [13] [14].

$\mathrm{SiO}_{2}$ nanoparticles caused better adhesion of the sol-gel coating film to the glass substrate due to the formation of $\mathrm{Si}-\mathrm{O}-\mathrm{Si}$ chemical bonds between $\mathrm{Si}-\mathrm{OH}$ groups from TEOS and the $\mathrm{Si}-\mathrm{OH}$ of the glass substrate [15] [16] [17]. $\mathrm{TiO}_{2}$ addition to coating provides appropriate physical and chemical properties and also obtained coating showed self-cleaning property which is related to durable oxidation power and super hydrophilic properties [16] [17].

Super-hydrophobic surfaces obtained by incorporation of micro and nanoscale binary structured composite particles of silica/fluoropolymer using an emulsion mediated sol-gel process, and then these composite particles were applied to various substrates to mimic the surface microstructures of lotus leaves (Scheme 1) [18].

To fabricate super-hydrophobic surfaces, both the surface chemical composition and morphology need to be tuned to achieve low surface energy and desirable surface roughness. Coatings incorporating silica nanoparticles, the excellent adhesion of the coating film to the glass substrate was due to the formation of $\mathrm{Si}-\mathrm{O}-\mathrm{Si}$ chemical bonds between $\mathrm{Si}-\mathrm{OH}$ groups from TMOS and TMSM and the $\mathrm{Si}-\mathrm{OH}$ of the glass substrate lead to high thermal and mechanical stability and high surface roughness [19].

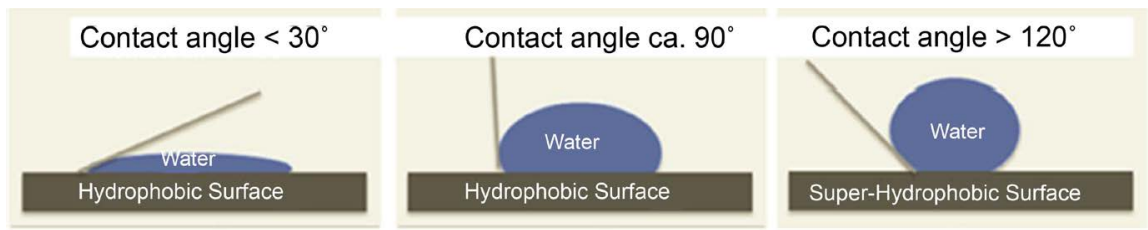

Scheme 1. Schematic diagram for super hydrophobic surfaces. 
Fluoroalkyl silanes have high chemical and mechanical stability. Due to that, it can immobilize through silicon bonding. This unique property makes it one of the best suitable materials among low surface energy substances [20].

In this research, $\mathrm{TiO}_{2}, \mathrm{SiO}_{2}$ were synthesized, and then self-assembled monolayers (SAMs) of ${ }^{1} \mathrm{H},{ }_{1}^{1} \mathrm{H},{ }^{2} \mathrm{H},{ }^{2} \mathrm{H}$-perfluorooctyltriethoxysilane (PFOTES) were grafted onto the silica and titan nanoparticle surface $\left(\mathrm{SiO}_{2}-\mathrm{TiO}_{2}\right.$-PFOTES, $\mathrm{SiO}_{2}$-PFOTES and $\mathrm{TiO}_{2}$-PFOTES hybrid nanocomposite coatings) via sol-gel and characterized by Fourier transform infrared spectroscopy (FTIR), Energy-dispersive X-ray spectroscopy (EDAX), Field Emission Scanning Electron Microscopy (FESEM). The hydrophobicity and durability of the coatings were investigated. Contact angles (CAs) of water and milk modified stainless steel mesh was measured by optical contact angle meter (OCA). Corrosion protection performance of the sol-gel-derived coatings was studied using electrochemical impedance spectroscopy (EIS) analysis.

\section{Experimental}

\subsection{Materials}

Tetraethylorthosilicate (TEOS, >96\%), 3-Glycidoxypropyltrimethoxysilane (GPTMS, $>97 \%$ ), hydrochloric acid ( $\mathrm{HCl}, 37 \%)$, ethanol ( $>98 \%)$, tetra (n-butyl orthotitanate, $>98 \%$ ) (TBT), acetylacetone (AcAc, >98\%), Isopropanol (>99\%) and nitric acid $\left(\mathrm{HNO}_{3}, 65 \%\right)$ were purchased from Merck and used as received. ${ }^{1} \mathrm{H},{ }^{1} \mathrm{H},{ }^{2} \mathrm{H},{ }^{2} \mathrm{H}$-Perfluorooctyltriethoxysilane (PFOTES, >98\%) and itaconic acid catalyst were obtained from Sigma-Aldrich. Polyol resin (3186) was purchased from Gohar Resin Company, and Isocyanates Aliphatic (N75) hardener was obtained from Desmodur Company.

\subsection{Synthesis of $\mathrm{SiO}_{2}$ Nanoparticles}

The hybrid sol was prepared by admixing silica precursors (GPTMS, TEOS. GPTMS, and TEOS) which were mixed (3:1 molar ratio) with $12.3 \mathrm{cc}$ of ethanol in a beaker while being stirred using a magnetic stirrer at $200 \mathrm{rpm}$ for 1 hour at ambient temperature. The resultant two-phase solution was then vigorously stirred at $240 \mathrm{rpm}$ for $4 \mathrm{~h}$. With its $\mathrm{pH}$ adjusted at 2, water served as the acidic catalyst. Hydrolysis and condensation of the silane were conducted at stoichiometric and $50 \%$ sub-stoichiometric water $\mathrm{pH}=2$, ethanol ratio in the presence of an acid catalyst. Once finished with hydrolysis and condensation, the sol was stirred at room temperature for 24 hours [16] [17].

\subsection{Synthesis of $\mathrm{TiO}_{2}$ Nanoparticles}

TBT and Isopropanol (1:23 molar ratio) were mixed and stirred by a magnetic stirrer $(200 \mathrm{rpm})$ at room temperature for $2 \mathrm{~h}$. Then, $0.31 \mathrm{cc}$ of AcAc was added into the mixture to control the rate of the hydrolysis reaction. The mixture was subsequently stirred at the same rate for $1 \mathrm{~h}$ to obtain a transparent solution. Next, $2.16 \mathrm{CC}$ of distilled water $\left(\mathrm{pH}=2\right.$, from $\left.\mathrm{HNO}_{3}\right)$ was added to the above 
solution in a drop-wise fashion, and the resulting solution was stirred at ambient temperature for $4 \mathrm{~h}[16]$ [17].

\subsection{Preparation of Substrates and Coating Technique}

To prepare nanocomposite coatings for different tests, first, iron substrates were cleaned as follows:

The iron sheets were cleaned with water and soap and washed by acetone. Then, they were washed with $5 \% \mathrm{w} / \mathrm{w} \mathrm{NaOH}$ solution at $60^{\circ} \mathrm{C}$ for 3 times and then washed with distilled water. Next, the above substrates were washed 3 times with $5 \% \mathrm{w} / \mathrm{w} \mathrm{HCl}$ solution and then washed with distilled water. Lastly, the substrates were washed with ethanol and dried at room temperate. Cleaned aluminum iron substrates were dip-coated in the as-prepared mixture and dried at ambient temperature for 24 hours and post cured at $130^{\circ} \mathrm{C}$ for 90 minutes [16] [17].

\subsection{Preparation of Low Surface Energy Coating Containing PFOTES, $\mathrm{SiO}_{2}$ and $\mathrm{TiO}_{2}$ Nanoparticles}

Polyurethane (PU) resin has been employed as polymeric matrix and N75 hardener as a curing agent to obtain low energy surface coating. $\mathrm{TiO}_{2}, \mathrm{SiO}_{2}, \mathrm{PDMS}$ and PFOTES nanoparticles with different proportion has been added to PU matrix in each sample (Table 1 ) to a $50 \mathrm{ml}$ beaker, at room temperature for $15 \mathrm{~min}$ stirred with speed of $200 \mathrm{rpm}$, then diluted with diluent (xylene or toluene) and stirring continued with same speed for $5 \mathrm{~min}$. The data of Table 1 are selected based on previous works in this area [7] [8] [9] [10] [11]. Hardener, silane, and TEOS were added to the obtained solution, using an Ultrasonic probe were placed in a vessel with the rated output power of $100 \mathrm{~W}$ and sonicated for $2 \mathrm{~min}$.

\subsection{Characterization}

Infrared spectra were recorded using objective FTIR on an Equinox 55 spectrometer (Bruker, Germany) in the range of 400 and $4000 \mathrm{~cm}^{-1}$. A field emission scanning electron microscope (FE-SEM) was used to investigate the surface morphology and microstructure of the nanocomposites. The FE-SEM instrument was a Tescan Mira3 (Czech Republic) with $15.0 \mathrm{kV}$ accelerating voltage in

Table 1. Formulation of obtained coating.

\begin{tabular}{|c|c|c|c|c|c|c|c|c|c|}
\hline Sample & $\begin{array}{c}\text { PFOTES } \\
\text { gr }\end{array}$ & $\begin{array}{c}\text { PDMS } \\
\text { gr }\end{array}$ & $\begin{array}{c}\mathrm{SiO}_{2} \\
\mathrm{gr}\end{array}$ & $\begin{array}{c}\mathrm{TiO}_{2} \\
\mathrm{gr}\end{array}$ & $\begin{array}{c}\text { Resin } \\
\text { gr }\end{array}$ & $\begin{array}{c}\text { N75 } \\
\text { gr }\end{array}$ & $\begin{array}{c}\text { Silane } \\
\text { gr }\end{array}$ & $\begin{array}{c}\text { TEOS } \\
\text { gr }\end{array}$ & $\begin{array}{c}\text { Xylene } \\
\text { Cc }\end{array}$ \\
\hline 1 & 0.2 & - & - & - & 2 & 0.59 & - & - & 0.5 \\
\hline 2 & 0.36 & 0.1 & 0.1 & 0.1 & 2 & 0.74 & 0.13 & 0.11 & - \\
\hline 3 & 0.014 & 0.1 & 0.12 & 0.1 & 2 & 0.59 & 0.1 & 0.1 & - \\
\hline 4 & 0.02 & 0.2 & 0.1 & 0.05 & 2 & 0.54 & - & - & 1 \\
\hline 5 & 0.01 & 0.25 & 0.04 & 0.07 & 2 & 0.56 & - & - & 1 \\
\hline 6 & 0.011 & 0.12 & 0.02 & - & 2 & 0.59 & - & - & 1 \\
\hline
\end{tabular}


the secondary electron imaging mode. Mapping of the distribution of $\mathrm{Si}, \mathrm{Ti}$ and F constituting the specimen was obtained through EDAX (INCA, Oxford Instruments, England) in coated aluminum substrates. Contact angle and tilt angle measurements were performed with an optical contact angle meter (OCA40 Micro, Dataphysics, Germany). The wettability of the film was determined by measuring the contact angles of two probe liquids, water $(\mathrm{g}=72.8 \mathrm{mN} / \mathrm{m})$, and milk $(\mathrm{g}=52.5 \mathrm{mN} / \mathrm{m})$. The hydrophobicity and the oleophilicity were measured respectively with $5 \mathrm{~mL}$ water and $5 \mathrm{~mL}$ milk. An average of five measurements taken at different positions on each sample was made to determine the hydrophobicity and oleophilicity of the film.

\subsection{Electrochemical Analysis of the Obtained Coating}

Electrochemical measurements were performed under extreme environmental conditions, consisting of aqueous, air-exposed sodium chloride $(5 \% \mathrm{NaCl})$ solution. Each sample was sealed with waterproof tape in order to prevent premature corrosion along the edges of the substrate. A $1 \mathrm{~cm} \times 1 \mathrm{~cm}$ area within the center of each sample was exposed to the solution during testing. Corrosion analysis of bare and coated substrates was done using an AutolabPGSTAT30 potentiostat system connected to a corrosion analysis software program. Polarization measurements were carried out potentiostatically at room temperature using an $\mathrm{Ag} / \mathrm{AgCl} / \mathrm{Cl}^{-}(0.222 \mathrm{~V})$ reference electrode and a platinum counter electrode. The potentiodynamic measurements were taken within the range of -2000 to $2000 \mathrm{mV}$ versus $\mathrm{Ag} / \mathrm{AgCl} / \mathrm{Clat}$ a rate of $5 \mathrm{mV} / \mathrm{s}$. Before the measurements, in order to reach steady potential, the electrodes were kept in the working solutions for at least $30 \mathrm{~min}$ [17].

\section{Results and Discussion}

Figure 1 and Figure 2 shows FTIR spectrum of pure $\mathrm{SiO}_{2}, \mathrm{TiO}_{2}, \mathrm{PU}, \mathrm{N} 75$, PFOTES nanoparticles and the obtained nanocomposite coating in the wavenumber range from 400 to $4000 \mathrm{~cm}^{-1}$. In Figure 1(a), the peak around $450-550$ $\mathrm{cm}^{-1}$ can be attributed to Si-O-Si, $935-970 \mathrm{~cm}^{-1}$ and $1070-1100 \mathrm{~cm}^{-1}$ attributed to $\mathrm{Si}-\mathrm{O}-\mathrm{C}_{2} \mathrm{H}_{5}, 1000-1100 \mathrm{~cm}^{-1}$ attributed to Si-O aliphatic, $1100-1240$ attributed to tertiary alcohol and $2800-300$ to $\mathrm{CH}_{2}$. Figure $1(\mathrm{~b})$, the broad absorption bands at regions $460 \mathrm{~cm}^{-1}$ and $820 \mathrm{~cm}^{-1}$ can be related to Ti-O stretching vibration [14] and $\mathrm{Ti}-\mathrm{O}-\mathrm{Ti}$ [15], respectively. A broad absorption band at around $3400 \mathrm{~cm}^{-1}$ and a sharp band at around $1616 \mathrm{~cm}^{-1}$, which are observed in all $\mathrm{TiO}_{2}$ spectra, can be assigned to the physically adsorbed water on the surface of $\mathrm{TiO}_{2}$ [16] [17].

Figure 1(c), the spectrum exhibits broad absorption peaks between 3400 $3600 \mathrm{~cm}^{-1}$, corresponding to the stretching mode of the $\mathrm{O}-\mathrm{H}$ group of hydroxyl group that is adsorbed on the surface of nanoparticles. The strong absorption peak at $3500 \mathrm{~cm}^{-1}$ refers to $\mathrm{O}-\mathrm{H}$ vibration, and also $\mathrm{C}-\mathrm{H}$ stretching vibrations at $2950 \mathrm{~cm}^{-1}$ is observed. $\mathrm{N} 75$ peaks are seen at 3650 to $340 \mathrm{~cm}^{-1}$ (hydroxyl group) 


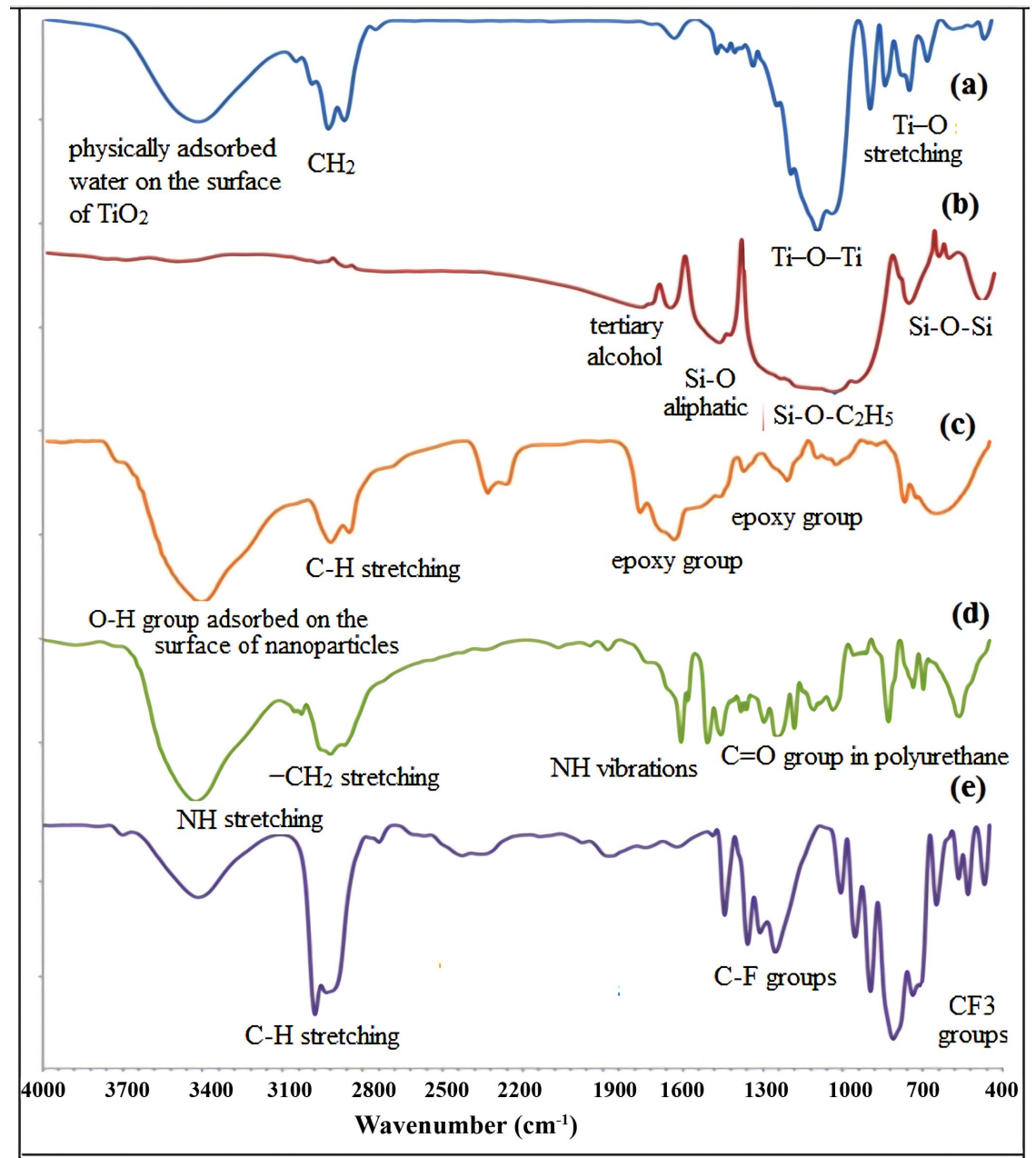

Figure 1. FTIR spectra of (a) $\mathrm{TiO}_{2}$, (b) $\mathrm{SiO}_{2}$, (c) N75, (d) PU, and (e) PFOTES.

and 925 to $899 \mathrm{~cm}^{-1}$ (epoxy group). Figure 1(d) shows FTIR peaks of PU which the absorption band at $3323 \mathrm{~cm}^{-1}$ corresponds to $\mathrm{NH}$ stretching, the sharp peaks at $2859 \mathrm{~cm}^{-1}$ and $2938 \mathrm{~cm}^{-1}$ are associated with $-\mathrm{CH}_{2}$ stretching, while other modes of $-\mathrm{CH}_{2}$ vibrations are identified by the bands at 1464, 1418, 1364, and $1294 \mathrm{~cm}^{-1}$. Besides, the absorption band at $1734 \mathrm{~cm}^{-1}$ is associated with a $\mathrm{C}=\mathrm{O}$ group in polyurethane. The group of $\mathrm{NH}$ vibrations is identified by the bands at $1541 \mathrm{~cm}^{-1}$ [11] [12] [13] [14].

The peaks at $2986 \mathrm{~cm}^{-1}$ and $2879 \mathrm{~cm}^{-1}$ are the stretching vibration band of $\mathrm{C}-\mathrm{H}$, which was probably caused by the impurities of PFOTES. The peaks at $1240 \mathrm{~cm}^{-1}$ and $1143 \mathrm{~cm}^{-1}$ represent the C-F groups. Thus, it is reasonable to believe that the PFOTES is grafted onto the marble's surface (Figure 1(e)).

The peaks at $1273,1191,1134$, and $1111 \mathrm{~cm}^{-1}$ for the PFOTES-TiO PFOTES-SiO ${ }_{2}$ and PFOTES- $\mathrm{SiO}_{2}-\mathrm{TiO}_{2}$ modified surface is attributed to the C- $\mathrm{F}_{2}$ group. The bands for $\mathrm{CF} 3$ in the range of $1110-1350 \mathrm{~cm}^{-1}$ and those at 820 and $890 \mathrm{~cm}^{-1}$. Also, the peaks at the region around $1397 \mathrm{~cm}^{-1}$ and $1074 \mathrm{~cm}^{-1}$ can be assigned to C-F bands [8] [9]. Therefore, the observed double band (1187 and $\left.1214 \mathrm{~cm}^{-1}\right)$ and a single band $\left(1135 \mathrm{~cm}^{-1}\right)$ in $\mathrm{F} 1-\mathrm{NC}$ spectrum, also a double 


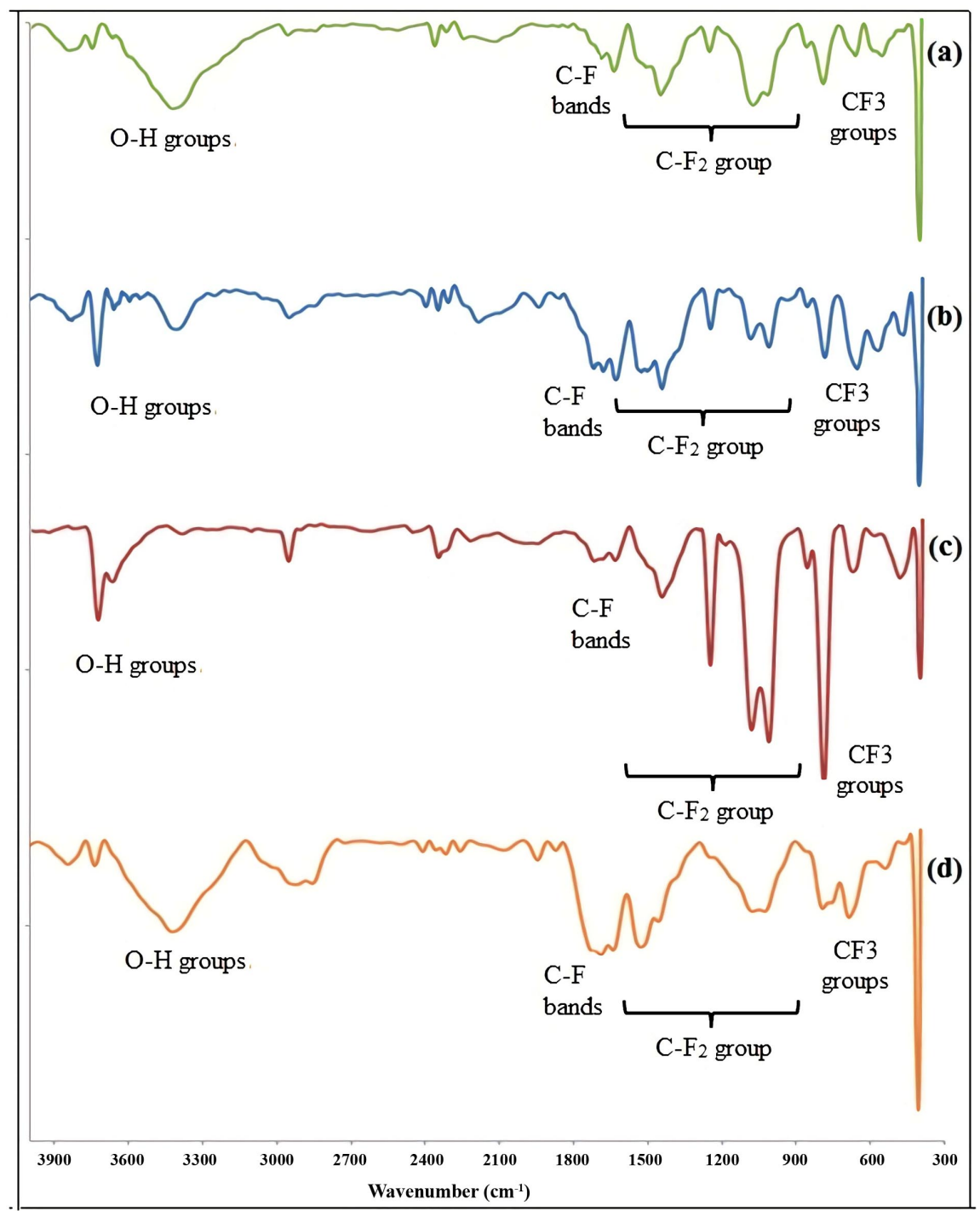

Figure 2. FTIR spectra of (a) sample 2, (b) sample 4, (c) sample 5, (d) sample 6.

bond (1186 and $\left.1232-1201 \mathrm{~cm}^{-1}\right)$ and a single bond $\left(1116 \mathrm{~cm}^{-1}\right)$ in F1-BC spectrum can be attributed to $\mathrm{C}-\mathrm{F}_{2}$. The peaks at $1350 \mathrm{~cm}^{-1}$ relates to $\mathrm{C}-\mathrm{F}_{3}$ vibration

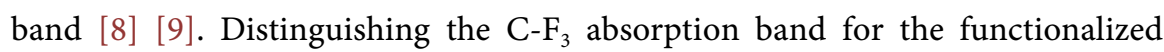
PFOTES-TiO 2 between 890 and $820 \mathrm{~cm}^{-1}$ is difficult since it overlaps with the $\mathrm{Ti}-\mathrm{O}-\mathrm{Ti}$ band that occurs in the same region. It can be confirmed that the hydrophilic property of pristine $\mathrm{TiO}_{2}$ nanoparticles was successfully modified to form hydrophobic particles by PFOTES. From the FTIR spectroscopy, it can be concluded that the utilized fluorosilane adsorbed on $\mathrm{TiO}_{2}$ and $\mathrm{SiO}_{2}$ surfaces [11] [12] [13] [14] [16] [17].

\subsection{Morphological and Nanoparticle Distribution Results}

Figure 3 and Figure 4 show morphological features of $\mathrm{SiO}_{2}$ and $\mathrm{TiO}_{2}$ hybrid nanocomposite coatings as recorded via field and a point EDAX technique. These figures indicate the uniform spherical distribution of nanoparticles within 

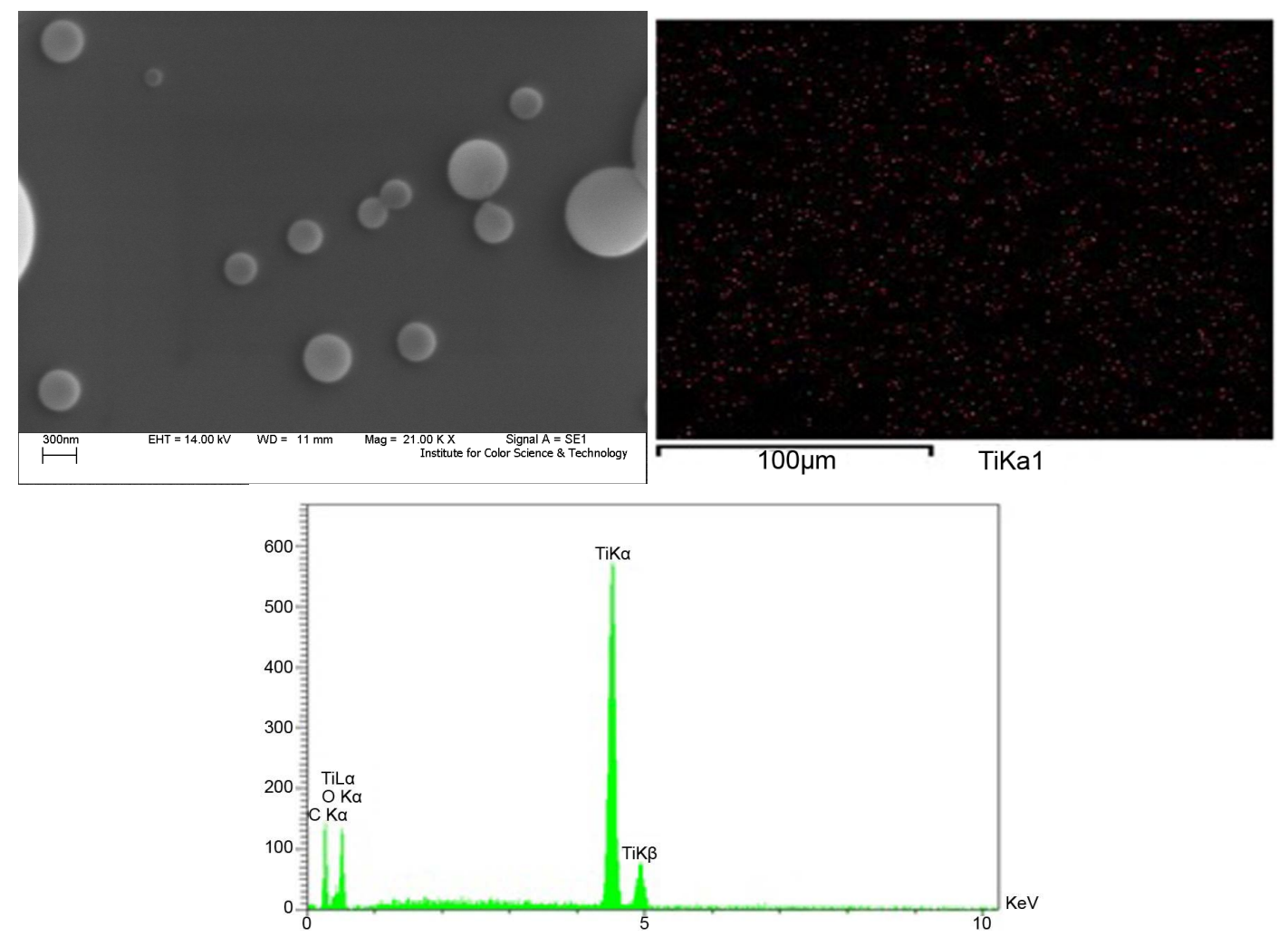

Figure 3. SEM and EDAX images mapping (Ti element) and pointed of a spherical particle of $\mathrm{TiO}_{2}$ hybrid nanocomposite coating.
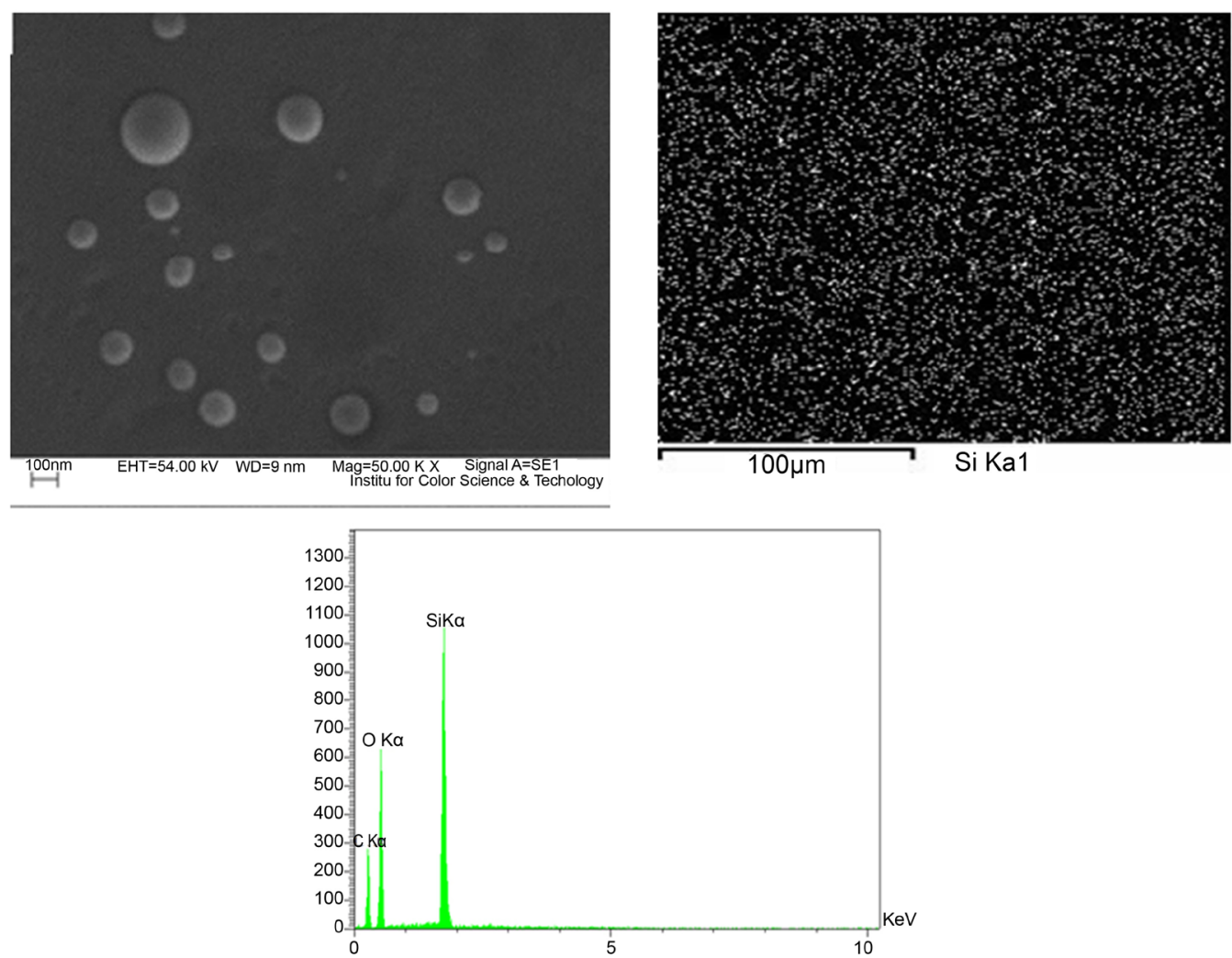

Figure 4. SEM and EDX image of $\mathrm{SiO}_{2}$ hybrid nanocomposite coating. 
hybrid coatings with no aggregation observed, and both titania and silica particles are spherical [16] [17]. In Figure 3 EDAX images mapping which shows a map of Ti elements distribution in $\mathrm{TiO}_{2}$ verifies well distribution of titania particles in the coating. Pointed EDAX of a spherical particle, confirmed that spherical particles are synthesized $\mathrm{TiO}_{2}$. Mohseni-Salehi et al. have somehow reported the same results (The presence of well-distributed particles) about $\mathrm{TiO}_{2}$ nanoparticle [21] [22]. It can be seen spherical particles of silica in Figure 4. It is shown the presence of $\mathrm{Si}$ elements similar before the discussion.

FESEM of $\mathrm{SiO}_{2}$ and $\mathrm{TiO}_{2}$ hybrid coating showed uniform, crack-free, and smooth morphology with a uniform dispersion of nanoparticles throughout the surface of the hybrid coating without any aggregation (Figure 5). No cracks and fracture are observed on the coating surface. Figure 5(a) shows a small diameter size of $\mathrm{TiO}_{2}$ particles for example from 19.45 to $15.36 \mathrm{~nm}$ in comparison with $\mathrm{SiO}_{2}$ diameter size Figure 5(b) from $7.85 \mathrm{~nm}$ to 15.36 .
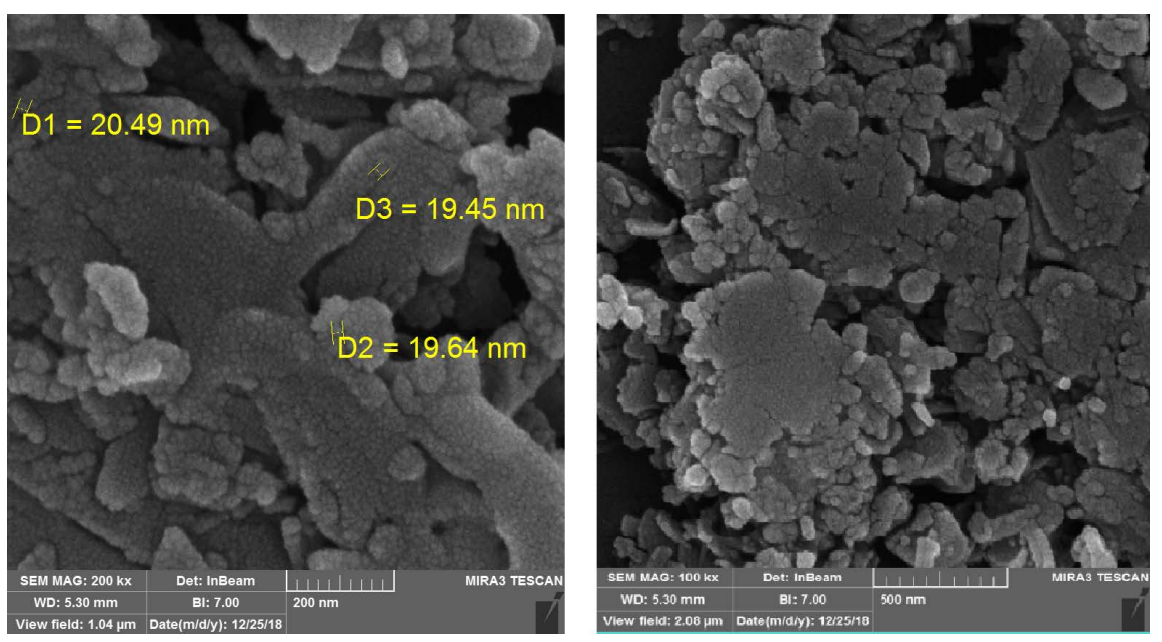

(a)
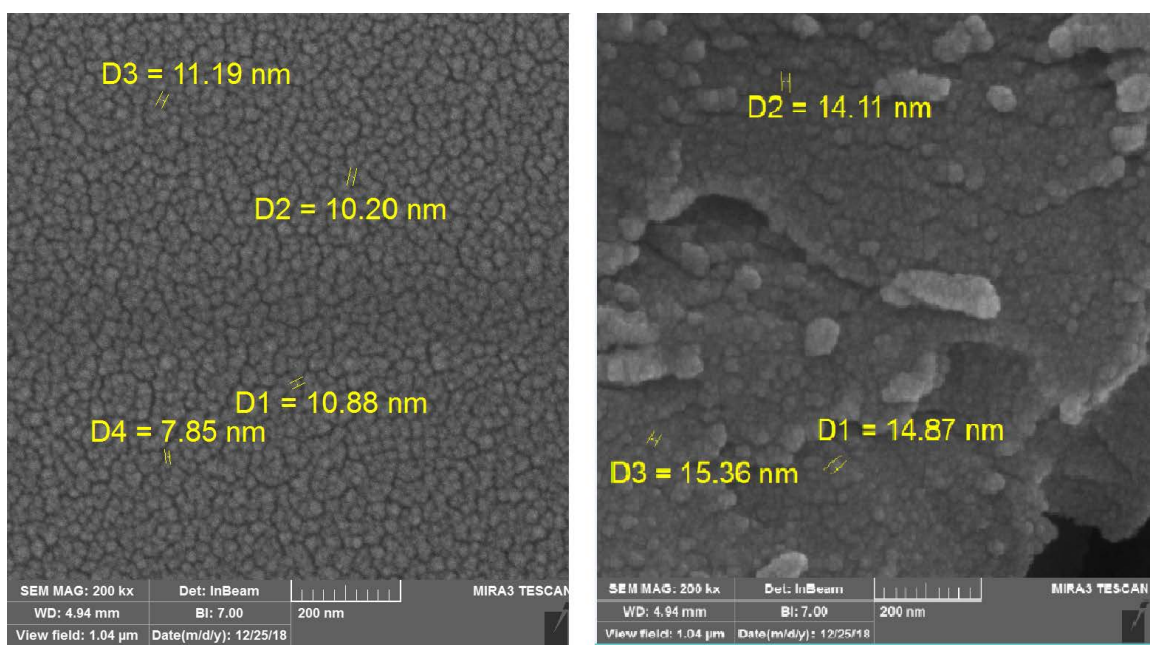

(b)

Figure 5. FESEM images of the hybrid nanocomposite coating containing (a) $\mathrm{TiO}_{2}$ and (b) $\mathrm{SiO}_{2}$. 


\subsection{Contact Angle Analysis}

In general, materials with a contact angle greater than $90^{\circ}$ can be called a hydrophobic material. They have two characteristics; one was low surface energy, and the other was a rough structure. Because PFOTES contained a large number of hydrophobic groups, it had low surface energy and a specific self-cleaning effect (Figure 6).

When hydrophilic $\mathrm{TiO}_{2}$ was added to the PFOTES, the coatings with micro-nano rough structure had a more significant amount of air, which blocks the entry of water, influencing the CA of the surface. On the other hand, the hydrophilic properties of the $\mathrm{TiO}_{2}$ coating would decrease the CA. When the content of $\mathrm{TiO}_{2}$ was low, the CA of the coating was decreased from 102 to 98 . The less content of $\mathrm{TiO}_{2}$ on the surface, the less number of micro-nano structures. Besides, the addition of $\mathrm{TiO}_{2}$ would increase the roughness of the composite coating, thereby increasing the CA. When the content of $\mathrm{TiO}_{2}$ was high (8 and 10 wt\%), it formed more micro-nano structures which changed the CA of the coating. The rough structure of the coating surface played a major role, and the $\mathrm{CA}$ of the coating was increased from $98^{\circ}$ to $108^{\circ}$. If the content of $\mathrm{TiO}_{2}$ was too high, the uniformity of $\mathrm{TiO}_{2}$ in the coating would be destroyed, causing a decreased CA of composite coatings [8] [9].

\subsection{EIS Measurement}

Finally, the corrosion behavior of the sol-gel hybrid coatings was also analyzed

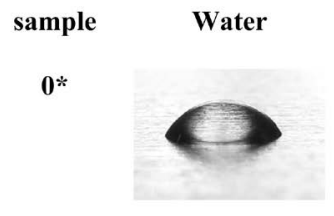

47.636

1

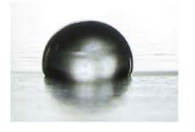

106.416

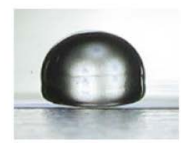

98.753

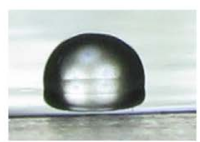

99.025

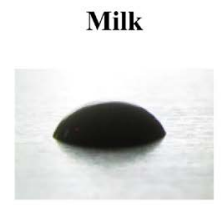

56.104

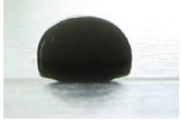

104.822

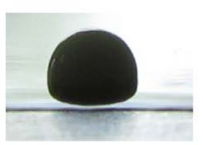

108.663

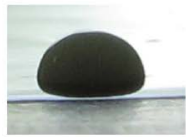

88.919
Water

$0 * *$

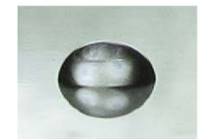

81.051

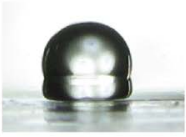

110.416

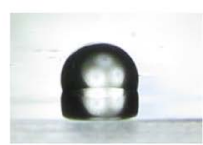

107.295

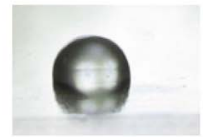

109.471
Milk

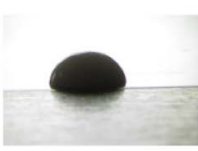

73.212

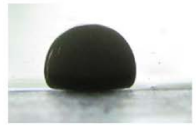

108.663

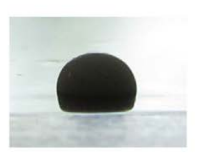

104.117

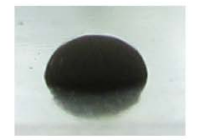

86.177

Figure 6. Contact angle of obtained coating. ${ }^{\star}$ Bare sample without any coating; ${ }^{\star \star}$ Bare sample coated with resin and N75. 
using electrochemical impedance spectroscopy (EIS) in $5 \% \mathrm{NaCl}$ aqueous solution. EIS measurements were done to investigate the anti-corrosion performance of the synthesized coatings. As complementary experiments, potentiodynamic polarization curves were plotted (Figure 7 and Figure 8) under extreme environmental conditions developed by aqueous, air-exposed sodium chloride (5\% $\mathrm{NaCl}$ ) solution. The values of each component of the equivalent circuit were similarly obtained when the specimen was immersed in a salt solution for different time durations, and the Rhealing of the PFOTES-based self-healing coating as a function of immersion time was plotted in Figure 5(b). It was seen that generally, the Rhealing of the self-healing coating exhibited an increasing trend. The healing increased from about $1.0 \times 103$ to $2.2 \times 103 \Omega$ when the immersion time increased from 2 to $24 \mathrm{~h}$ [16] [20] [23] [24] [25] [26].

The potentiodynamic polarization curves in Figure 8 show that the destructive behavior of the alloys with a coating containing nanoparticles $\left(\mathrm{SiO}_{2} / \mathrm{TiO}_{2}\right.$, PFOTES/TiO 2 , PFOTES/SiO ${ }_{2}$, and $\mathrm{SiO}_{2} / \mathrm{TiO}_{2} / \mathrm{PFOTES}$ ) is very different to the

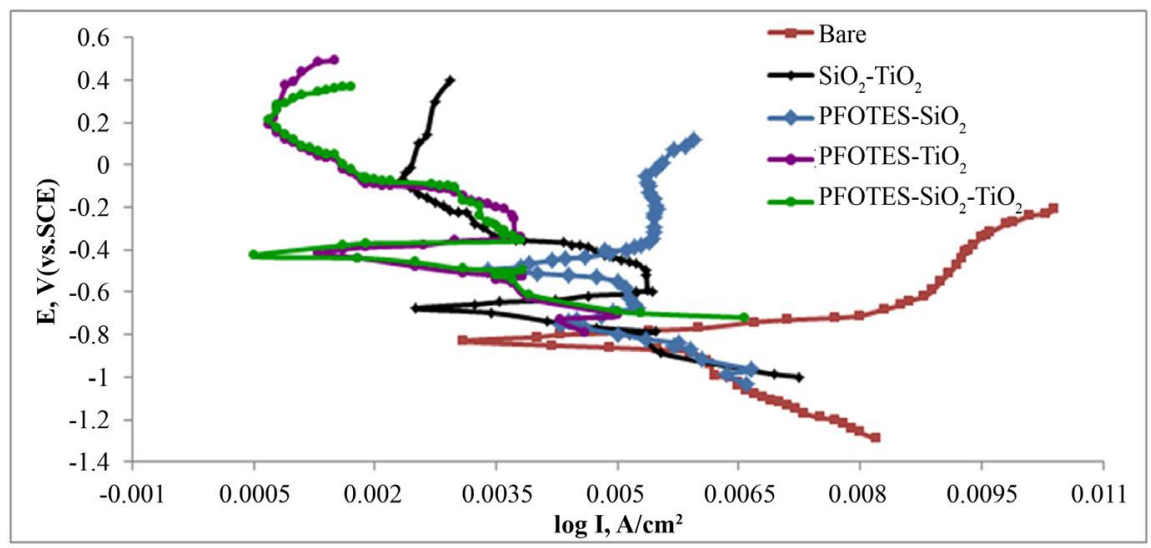

Figure 7. Potentiodynamic scans for coating containing encapsulated inhibitor under different conditions in diluted $5 \% \mathrm{NaCl}$ solution.

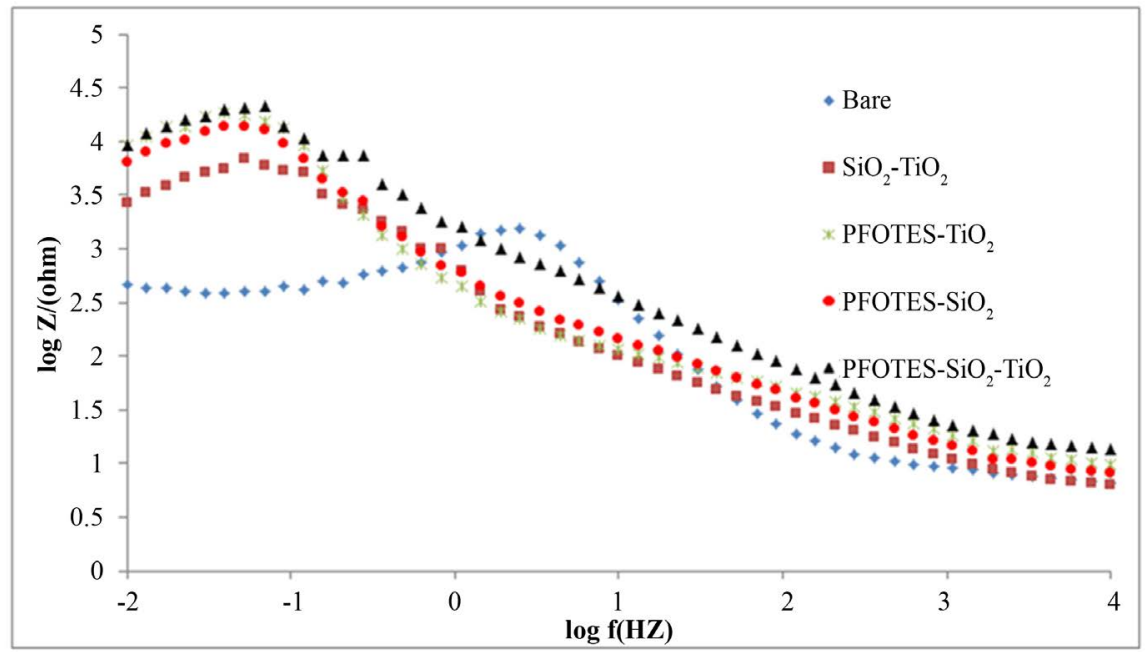

Figure 8. Electrochemical impedance spectra for scribed coatings with different inhibitor nanocontainers in $5 \% \mathrm{NaCl}$ solution. 
observed for the alloy without protective coating (identified as "bare" in Figure 7 and Figure 8). The protected alloys display very resistive behaviors with shallow current density values (in the range from $10-14$ to $5 \times 10-11 \mathrm{~A} \mathrm{~cm}^{-2}$ ), which are typical of non-conductive materials, like the ceramic coatings. Note that the polarization curves of the alloys with a coating containing nanoparticles were carried out in an extensive range of potentials, between -1.4 and $0.6 \mathrm{~V}$ versus SCE $(2.5 \mathrm{~V})$, which is higher than the commonly used range as observed for the bare alloy. A decrease in corrosion current density is observed in the samples coated with $\mathrm{SiO}_{2} / \mathrm{TiO}_{2}, \mathrm{SiO}_{2} / \mathrm{PFOTES}, \mathrm{TiO}_{2} / \mathrm{PFOTES}$, and PFOTES $/ \mathrm{SiO}_{2} / \mathrm{TiO}_{2}$ coatings; this is important when it comes to corrosion protection for the alloy. Addition of $\mathrm{TiO}_{2}, \mathrm{SiO}_{2}$ and PFOTES nanoparticles to the hybrid coatings was seen to increase the hardness of coatings and improve their corrosion resistance. This effect is a result of a particular size and extreme aspect ratio of these nanoparticles which reduced the space between the particles and coating to far less than that of larger particles. It may also be attributed to good dispersion of nanoparticles which enhances the density of the coating films containing nanoparticles, thereby increasing the transport paths for the corrosive electrolyte to pass through the coating and reduce the extent of corrosion process consequently [16] [20] [23] [24] [25] [26].

For $\mathrm{SiO}_{2} /$ PFOTES and $\mathrm{TiO}_{2} /$ PFOTES coatings, samples loaded with $\mathrm{TiO}_{2} \mathrm{NPs}$ show a higher impedance value in comparison with the samples without $\mathrm{TiO}_{2} \mathrm{NPs}$ (bare sample and $\mathrm{SiO}_{2} /$ PFOTES coating). The presence of these $\mathrm{TiO}_{2}$ NPs has a beneficial impact on the sol-gel hybrid coating resistance, since the impedance values at low frequency are increased, and as a result, an enhancement of the barrier properties. PFOTES containing coatings showed a good anticorrosive performance. The experimental results indicate a direct relationship between both the hydrophobic property and corrosion resistance (Figure 7). The highest hydrophobicity is related to PFOTES $/ \mathrm{SiO}_{2} / \mathrm{TiO}_{2}$ coating (the highest WCA value) in comparison with the sol-gel coated samples without PFOTES precursor. Presence of a hydrophobic layer in the outer surface acts as a physical diffusion barrier due to the entrapment of air between the roughness protrusions, so the coated sample shows a good anti-corrosion property. EIS experimental results clearly demonstrate that the combination of both metal oxide nanoparticles $\left(\mathrm{TiO}_{2} \mathrm{NPs}\right)$ and the use of PFOTES precursor in the outer surface for increasing the hydrophobicity allows the design of novel coatings, which can considerably reduce the corrosion susceptibility, while showing very good mechanical properties due to the presence of these metal oxide nanoparticles inside the sol-gel hybrid coatings. However, the impedance values were lower for the bare sample, indicating that the coating was beginning to delaminate, which is more likely to happen within the scribed area as a result of corrosion attack at the coating/substrate interface (Figure 8).

Table 2 showed corrosion rates of uncoated samples and samples coated with nanoparticles which indicated that coating containing PFOTES and $\mathrm{TiO}_{2}$ provides 
Table 2. Associated corrosion rates with bare non-coated samples and the samples coated with inhibitor nanocontainers.

\begin{tabular}{cccccc}
\hline & Bare sample & $\mathrm{SiO}_{2} / \mathrm{TiO}_{2}$ & $\mathrm{PFOTES} / \mathrm{SiO}_{2}$ & $\mathrm{PFOTES} / \mathrm{TiO}_{2}$ & $\mathrm{SiO}_{2} / \mathrm{TiO}_{2} / \mathrm{PFOTES}$ \\
\hline Protection (\%) & 78.14 & 83.15 & 86.47 & 91.47 & 94.65 \\
\hline
\end{tabular}

better protection than $\mathrm{SiO}_{2}$. The impedance values for the bare sample rapidly decrease indicating that coating is starting to delaminate, which is more likely to happen within the scribed area as a result of corrosion attack to the coating/substrate interface [10] [11] [12].

\section{Conclusions}

In this research, novel superoleophobic sol-gel hybrid nanocomposite coating was prepared via sol-gel process. The obtained coatings were investigated by FTIR, SEM, EDAX, and FESEM analyses. SEM, FESEM and EDAX results indicated the uniform distribution and dispersion of the inorganic nanoparticles in the range of $10-30 \mathrm{~nm}$ within the polymer matrix, with no indication of agglomeration.

It has been demonstrated that the presence of these $\mathrm{TiO}_{2} \mathrm{NPs}$ produces a surface modification with an enhancement of the wettability of the coating, showing higher water contact angle (WCA) values. However, in order to increase the resultant hydrophobicity of the coatings, a new silica precursor based on fluorinated polymeric chains (PFOTES) has been added to the previous sol-gel hybrid matrix. The results reveal that the sol-gel coatings have shown an effective modification, because an essential improvement of the hydrophobicity has been observed. Also, the pencil hardness test has shown a considerable enhancement of the mechanical characteristics due to the thermal post-treatment (curing step). In order to evaluate the corrosion resistance of the sol-gel hybrid coatings, potentiodynamic polarization tests, as well as electrochemical impedance spectroscopy, has been performed. Finally, the experimental results clearly demonstrate that the combination of both metal oxide nanoparticles $\left(\mathrm{TiO}_{2} \mathrm{NPs}\right)$ in the inner part of the coating and PFOTES precursor in the outer surface enables the development of novel coatings with good mechanical durability, which can reduce the corrosion susceptibility by showing an excellent protective barrier for more extended periods of time. Also, good self-healing performance of the PFOTES-based coating was demonstrated by EIS measurements. The results revealed that the scratched coating was autonomously self-healed due to the formation and increment of a new film formed within the scratches during exposure to a salt solution, which was in agreement with the simulated self-healing parameter in an equivalent electrochemical circuit.

\section{Conflicts of Interest}

The authors declare no conflicts of interest regarding the publication of this paper. 


\section{References}

[1] Wang, D. and Bierwagen, G.P. (2009) Sol-Gel Coatings on Metals for Corrosion Protection. Progress in Organic Coatings, 64, 327-338. https://doi.org/10.1016/j.porgcoat.2008.08.010

[2] Mechtel, M., Mager, M. and Kraus, H. (2002) Sol-Gel: A New Tool for Coatings Chemistry. Progress in Organic Coatings, 45, 159-164. https://doi.org/10.1016/S0300-9440(02)00045-0

[3] Amiri, S. and Amiri, S. (2017) Chapter 4, Cyclodextrins: Properties and Industrial Applications. John Wiley \& Sons, New York. https://doi.org/10.1002/9781119247609

[4] Amiri, S. and Rahimi, A. (2017) Hybrid Nanocomposite Coating by Sol-Gel Method: A Review. Iranian Polymer Journal, 25, 559-577.

https://doi.org/10.1007/s13726-016-0440-x

[5] Ershad-Langroudi, A., Mai, C., Vigier, G. and Vassoille, R. (1997) Hydrophobic Hybrid Inorganic-Organic Thin Film Prepared by Sol-Gel Process for Glass Protection and Strengthening Applications. Journal of Applied Polymer Science, 65, 2387-2393.

https://doi.org/10.1002/(SICI)1097-4628(19970919)65:12<2387::AID-APP11>3.0.C $\underline{\mathrm{O} ; 2-\mathrm{Z}}$

[6] Darmanin, T., Givenchy, E.T., Amigoni, S. and Guittard, F. (2013) Superhydrophobic Surfaces by Electrochemical Processes. Advanced Materials, 25, 1378-1394. https://doi.org/10.1002/adma.201204300

[7] Ishizaki, T., Masuda, Y. and Sakamoto, M. (2011) Corrosion Resistance and Durability of Superhydrophobic Surface Formed on Magnesium Alloy Coated with Nanostructured Cerium Oxide Film and Fluoroalkylsilane Molecules in Corrosive $\mathrm{NaCl}$ Aqueous Solution. Langmuir, 27, 4780-4788.

https://doi.org/10.1021/la2002783

[8] Yuan, S. and Pehkonen, S.O. (2011) Superhydrophobic Fluoropolymer-Modified Copper Surface via Surface Graft Polymerisation for Corrosion Protection. Corrosion Science, 53, 2738-2747. https://doi.org/10.1016/j.corsci.2011.05.008

[9] Huang, M. and Yang, J. (2014) Long-Term Performance of $1 \mathrm{H}, 1 \mathrm{H}^{\prime}, 2 \mathrm{H}$, 2H'-Perfluorooctyl Triethoxysilane (POTS) Microcapsule-Based Self-Healing Anticorrosive Coatings. Journal of Intelligent Material Systems and Structures, 25, 98-106. https://doi.org/10.1177/1045389X13505785

[10] Lin, C.C., Hsu S.H., Chang, Y.L. and Su, W.F. (2010) Transparent Hydrophobic Durable Low Moisture Permeation Poly (Fluoroimide Acrylate) $/ \mathrm{SiO}_{2}$ Nanocomposite from Solventless Photocurable Resin System. Journal of Materials Chemistry, 20, 3084-3091. https://doi.org/10.1039/b924726b

[11] Zhao, Y., Xu, L. and Wang, Y. (2004) Preparation of Ti-Si Mixed Oxides by Sol-Gel One Step Hydrolysis. Catalysis Today, 93, 583-588. https://doi.org/10.1016/j.cattod.2004.06.124

[12] Zeitler, V.A. and Brown, C.A. (1957) The Infrared Spectra of Some Ti-O-Si, Ti-O-Ti and Si-O-Si Compounds. The Journal of Physical Chemistry, 61, 1174-1177. https://doi.org/10.1021/j150555a010

[13] Deng, C., James, P.F. and Wright, P.V. (1998) Poly (Tetraethylene Glycol Malonate)-Titanium Oxide Hybrid Materials by Sol-Gel Methods. Journal of Materials Chemistry, 8, 153-159. https://doi.org/10.1039/a703624h

[14] Hosseini-Zori, M. (2011) Synthesis of $\mathrm{TiO}_{2}$ Nanoparticles by Microemulsion/Heat 
Treated Method and Photodegradation of Methylene Blue. Journal of Inorganic and Organometallic Polymers and Materials, 21, 81-90. https://doi.org/10.1007/s10904-010-9419-9

[15] Estekhraji, S.A.Z. and Amiri, S. (2017) Sol-Gel Preparation and Characterization of Antibacterial and Self-Cleaning Hybrid Nanocomposite Coatings. Journal of Coatings Technology and Research, 14, 1335-1343. https://doi.org/10.1007/s11998-017-9932-7

[16] Estekhraji, S.A.Z. and Amiri, S. (2017) Synthesis and Characterization of Anti-Fungus, Anti-Corrosion and Self-Cleaning Hybrid Nanocomposite Coatings Based on Sol-Gel Process. Journal of Inorganic and Organometallic Polymers and Materials, 27, 883-891. https://doi.org/10.1007/s10904-017-0532-x

[17] Hosseini-Zori, M. (2018) Co-Doped $\mathrm{TiO}_{2}$ Nanostructures as a Strong Antibacterial Agent and Selfcleaning Cover: Synthesis, Characterization and Investigation of Photocatalytic Activity under UV Irradiation. Journal of Photochemistry \& Photobiology, B: Biology, 178, 512-520. https://doi.org/10.1016/j.jphotobiol.2017.12.008

[18] Li, X., Du, X. and He, J. (2010) Self-Cleaning Antireflective Coatings Assembled from Peculiar Mesoporous Silica Nanoparticles. Langmuir, 26, 13528-13534. https://doi.org/10.1021/la1016824

[19] Zhang, F., Chen, S. and Dong, L. (2011) Preparation of Superhydrophobic Films on Titanium as Effective Corrosion Barriers. Applied Surface Science, 257, 2587-2591. https://doi.org/10.1016/j.apsusc.2010.10.027

[20] Amiri, S. and Rahimi, A. (2016) Anticorrosion Behavior of Cyclodextrins/Inhibitor Nanocapsule-Based Self-Healing Coatings. Journal of Coatings Technology and Research, 13, 1095-1102. https://doi.org/10.1007/s11998-016-9824-2

[21] Mohseni-Salehi, M.S., Taheri-Nassaj, E. and Hosseini-Zori, M. (2018) Effect of Dopant (Co, Ni) Concentration and Hydroxyapatite Compositing on Photocatalytic Activity of Titania towards Dye Degradation. Journal of Photochemistry and Photobiology A: Chemistry, 356, 57-70. https://doi.org/10.1016/j.jphotochem.2017.12.027

[22] Mohseni-Salehi, M.S., Taheri-Nassaj, E. and Hosseini-Zori, M. (2018) Study on Cytotoxicity and Photocatalytic Properties of Different Titania/Hydroxyapatite Nanocomposites Prepared with a Combination of Sol-Gel and Precipitation Methods. Research on Chemical Intermediates, 44, 1945-1962.

https://doi.org/10.1007/s11164-017-3208-9

[23] Amiri, S. and Rahimi, A. (2014) Preparation of Supramolecular Corrosion-Inhibiting Nanocontainers for Self-Protective Hybrid Nanocomposite Coatings. Journal of Polymer Research, 21, 566.

https://doi.org/10.1007/s10965-014-0566-5

[24] Rahimi, A. and Amiri, S. (2015) Self-Healing Hybrid Nanocomposite Coatings with Encapsulated Organic Corrosion Inhibitors. Journal of Polymer Research, 22, 624. https://doi.org/10.1007/s10965-014-0624-Z

[25] Amiri, S. and Rahimi, A. (2015) Synthesis and Characterization of Supramolecular Corrosion Inhibitor Nanocontainers for Anticorrosion Hybrid Nanocomposite Coatings. Journal of Polymer Research, 22, 66. https://doi.org/10.1007/s10965-015-0699-1

[26] Rahimi, A. and Amiri, S. (2015) Anticorrosion Hybrid Nanocomposite Coatings with Encapsulated Organic Corrosion Inhibitors. Journal of Coatings Technology and Research, 12, 587-593. https://doi.org/10.1007/s11998-015-9657-4 